\title{
Hyperosmolar hyperglycemic nonketotic syndrome (HHNS)
}

National Diabetes Information Clearinghouse (NDIC)

\section{Definitions}

Blood glucose level

Defined by National Diabetes Information Clearinghouse (NDIC)

Ketone

Defined by National Diabetes Information Clearinghouse (NDIC)

Urine

Defined by National Diabetes Information Clearinghouse (NDIC)

Coma

Defined by National Diabetes Information Clearinghouse (NDIC)

\section{Source}

National Diabetes Information Clearinghouse (U.S.). (2009). The diabetes dictionary. [Bethesda, Md.]: U.S. Dept. of Health and Human Services, National Institutes of Health, National Institute of Diabetes and Digestive and Kidney Diseases, National Diabetes Information Clearinghouse.

An emergency condition in which one's blood glucose level is very high and ketones are not present in the blood or urine. If HHNS is not treated, it can lead to coma or death. 